\title{
Spontaneous resolution of severe chronic glue ear in children and the effect of adenoidectomy, tonsillectomy, and insertion of ventilation tubes (grommets)
}

\author{
Richard Maw, Rachel Bawden
}

\begin{abstract}
Objective-To measure the time to spontaneous resolution of severe chronic otitis media with effusion (glue ear) in children and study the effects of adenoidectomy, adenotonsillectomy, and ventilation tubes (grommets).
\end{abstract}

Design-Randomised controlled study over 12 years.

Setting-Paediatric otorhinolaryngology clinics and in-patient unit.

Subjects-228 children aged 2-9 years with pronounced hearing loss from glue ear and persistent bilateral middle ear effusions confirmed on three occasions over three months.

Interventions-Children were randomly allocated to adenotonsillectomy, adenoidectomy, or neither procedure. In all groups a Shepard type ventilation tube was inserted in one randomly chosen ear. Follow up was annually for five years and then less often for up to seven years four months. For analysis the two operated groups were combined.

Main outcome measures-Otoscopic clearance of fluid, change in tympanogram, and improvement in mean audiometric hearing threshold.

Results-Survival analysis showed appreciable otoscopic and tympanometric resolution of fluid with ventilation tubes alone and adenoidectomy alone compared with no surgery. Further improvement was seen after combination of both treatments. Mean audiometric hearing thresholds improved with fluid resolution. Resolution was delayed in younger children and in those whose parents smoked, irrespective of treatment. Whereas a single insertion of a Shepard tube resolved the glue for a mean (SD) period of $9.5(5.2)$ months, the effect of adenoidectomy was sustained throughout follow up.

Conclusions-Treatment of glue ear considerably shortened the time to fluid resolution, combined adenoidectomy and tube insertion being better than either procedure alone. Resolution was longer in younger children and those whose parent(s) smoked, irrespective of treatment.

\section{Introduction}

Chronic otitis media with effusion, or glue ear, is the commonest reason in children for elective admission to hospital for surgery. Possible treatment includes myringotomy with or without insertion of a ventilation tube (grommet) either alene or with adenoidectomy and occasionally tonsillectomy. The criteria for surgical intervention are uncertain, and the decision to operate has always been considered difficult in view of the high rate of spontaneous resolution. ${ }^{1}$ This is particularly associated with the child's age and the presence or absence of intercurrent infection, which is often seasonally related.

No data are available to show how long fluid persists in severe cases that would normally have been listed for surgery. This randomised controlled study began in August 1979, and recruitment continued until June 1986. Most of the children were referred by senior clinical medical officers (audiology). Some were direct referrals from general practitioners. The study was designed to show the outcome of chronic glue ear not submitted to any surgical treatment compared with that treated by adenoidectomy and adenotonsillectomy. Insertion of a ventilation tube in only one ear enabled us to assess this procedure both alone and in combination with adenoidectomy and adenotonsillectomy. In 1983 the initial results after 12 months were reported, which showed the effects with assessment by otoscopic examination. ${ }^{2}$ In 1986 the results at 12 months were reported with tympanometry and audiometry. ${ }^{3}$ The design of this study is now well known and has been analysed by other workers. ${ }^{4}$ This report presents the long term findings up to 12 years after inclusion in the study.

\section{Subjects and methods}

The methods have previously been reported..$^{23}$ District ethical committee approval was given and informed consent obtained from the parents. There were five entry criteria: (a) age between 2 and 11 years (but none were over 9); (b) pronounced subjective hearing loss; (c) pneumatic otoscopic confirmation of fluid in the middle ear of both ears; (d) tympanometry not showing a type A peaked curve (98\% type B, $2 \%$ type $\mathrm{C} 1$ or $\mathrm{C} 2$ ); and $(e)$ in excess of $25 \mathrm{~dB}$ pure audiometric or free field hearing loss in each ear at one or more frequencies.

From an initial population of 472 children, 228 satisfied the five criteria at each of three preoperative assessments separated by intervals of six weeks. The remainder were not followed up further. By using tables of random numbers the children were allocated to three groups: adenotonsillectomy, adenoidectomy, and no surgery. Each child then received a Shepard ventilation tube in a randomly chosen ear. This allowed the child to "hear" while the study progressed. The contralateral unoperated ear received no treatment but was examined under magnification $(6 x)$ to confirm the presence of fluid.

For ethical reasons a new tube had to be inserted when the original tubc extruded, fluid recurred in the operated ear, and the unoperated ear still contained fluid and showed subjective and audiometric loss of hearing. New tubes were always inserted in the same ear.

The homogeneity of the three groups has been reported for a wide variety of preoperative variables including age, sex, type of fluid, allergy, seasonal variation, radiographic determination of the size of the adenoids and postnasal space, and duration of preoperative loss of hearing. ${ }^{3}$ Assessment of the first 150 cases after one year in April 1983 confirmed that tonsillectomy had no additional benefit compared with adenoidectomy alone. Children were then allocated at random to the two remaining groups of adenoidectomy or no surgery in addition to unilateral insertion of ventilation tubes until June 1986, thus accounting for the reduced numbers at follow up in the later years. The unique design of this study allowed examination of 
outcome in an unoperated ear in a group of children who did not receive surgery to either the tonsils or adenoids. In effect, this group of ears represents the natural history of the untreated condition. These data can be compared with the outcome in ears treated with a ventilation tube or adenoidectomy or both. For the purposes of analysis the children who received adenotonsillectomy were grouped with those receiving adenoidectomy alone. Homogeneity was maintained.

During follow up of the 228 children six were excluded because they moved out of the area or because of poor attendance. Of these, four were from the no surgery group and two from the adenoidectomy group. Of the final 222 children, 139 were in the adenoidectomy and adenotonsillectomy group and 83 in the no surgery group. Table I shows the details of times of follow up.

The analysis focused on three procedures: otoscopy, tympanometry, and audiometry. With few exceptions all otoscopic examinations were performed blind by a single validated otoscopist (RM). ${ }^{5}$ The ears were examined and the presence or absence of fluid was noted before inspection of the case notes or pharynx.

Tympanometry was performed to assess the presence (type A, C1, or C2) or absence (type B) of a tympanometric peak. Pure tone audiometry was carried out by an audiological technician or scientist under sound proof conditions unless, according to age, free field audiometric assessment was required. Free field audiometry was carried out preoperatively in only 25 children, who were thus excluded from the audiometric analysis. This did not notably affect the age distribution of either group. A further six were excluded from the audiometric analysis because of unreliable preoperative audiometric data, leaving 118 in the adenoidectomy group and 73 in the other. Audiometry and tympanometry were also performed blind. The improvement in the mean of the pure tone audiometric thresholds at six frequencies from $250 \mathrm{~Hz}$ to $8 \mathrm{kHz}$ was calculated for each follow up time.

The results of the postoperative otoscopic and tympanometric assessments enabled estimation of the duration of glue ear to be made. From a questionnaire given to parents the reported duration of hearing loss

TABLE I-Times of follow up for assessment at each postoperative examination

\begin{tabular}{lll}
\hline Year & \multicolumn{1}{c}{ Range } & \multicolumn{1}{c}{$\begin{array}{c}\text { Mean (to } \\
\text { nearest month) }\end{array}$} \\
\hline $6 / 12$ & 4.5-7.5 Months & 6 Months \\
1 & $7 \cdot 5-18$ Months & 1 Year \\
2 & 1 Year 9 months-2 years 3 months & 2 Years \\
3 & 2 Years 6 months-3 years 6 months & 3 Years \\
4 & 3 Years 6 months-4 years 6 months & 4 Years \\
5 & 4 Years 6 months-5 years 6 months & 5 Years \\
7 & 5 Years 6 months-8 years 6 months & 7 Years \\
10 & 8 Years 6 months-12 years 4 months & 10 Years 1 month \\
\hline
\end{tabular}

TABLE II-Numbers (percentages) of cases excluded from otoscopic and tympanometric analysis

\begin{tabular}{|c|c|c|c|c|}
\hline \multirow[b]{2}{*}{ Reason for exclusion } & \multirow[b]{2}{*}{$\begin{array}{c}\text { No surgery } \\
\quad(n=77)\end{array}$} & \multirow[b]{2}{*}{$\begin{array}{l}\text { Tube only } \\
(\mathrm{n}=77)\end{array}$} & \multicolumn{2}{|c|}{ Adenoidectomy } \\
\hline & & & $\begin{array}{c}\text { Alone } \\
(n=136)\end{array}$ & $\begin{array}{c}\text { With tube } \\
(n=136)\end{array}$ \\
\hline \multicolumn{5}{|c|}{ Otoscopic analysis } \\
\hline $\begin{array}{l}\text { Fluid persisting at previous attendance(s) } \\
\text { Insertion of ventilation tube } \\
\text { Removal of adenoids and/or tonsils } \\
\text { Removal of adenoids and/or tonsils with ventilation tube } \\
\text { Insertion of Goode tube } \\
\text { Other (eg, myringotomy) } \\
\text { Total }\end{array}$ & $\begin{array}{l}15(47) \\
4(13) \\
11(34) \\
2(6) \\
0 \\
0 \\
32\end{array}$ & $\begin{array}{l}6(24) \\
- \\
10(40) \\
0 \\
9(36) \\
0 \\
25\end{array}$ & $\begin{array}{l}18(86) \\
0 \\
0 \\
0 \\
0 \\
3(14) \\
21\end{array}$ & $\begin{array}{l}7(78) \\
- \\
0 \\
0 \\
2(22) \\
0 \\
9\end{array}$ \\
\hline \multicolumn{5}{|c|}{ Tympanometric analysis } \\
\hline $\begin{array}{l}\text { Fluid persisting at previous attendance(s) } \\
\text { Insertion of ventilation tube } \\
\text { Removal of adenoids and/or tonsils } \\
\text { Removal of adenoids and/or tonsils with ventilation tube } \\
\text { Insertion of Goode tube } \\
\text { Other (eg, myringotomy) } \\
\text { Total }\end{array}$ & $\begin{array}{l}26(58) \\
4(9) \\
13(29) \\
2(4) \\
0 \\
0 \\
45\end{array}$ & $\begin{array}{l}15(45) \\
- \\
11(33) \\
0 \\
7(21) \\
0 \\
33\end{array}$ & $\begin{array}{l}31(91) \\
0 \\
0 \\
0 \\
0 \\
3(9) \\
34\end{array}$ & $\begin{array}{l}19(83) \\
0 \\
0 \\
4(17) \\
0 \\
23\end{array}$ \\
\hline
\end{tabular}

preoperatively was added to the three months of observation and to the duration of the condition postoperatively to give an overall estimate. Because of missing data on preoperative loss of hearing three cases of adenoidectomy and six of no surgery were excluded from the survival analysis. Hence 135 cases of adenoidectomy and 77 of no surgery were considered.

Because of the fluctuating nature of the condition strict criteria were required for defining the time when the fluid ceased to persist; when type $\mathrm{B}$ tympanograms changed to type $\mathrm{A}, \mathrm{C} 1$, or $\mathrm{C} 2$; and when an observation was stopped. Each ear of each child was investigated separately, thus enabling the comparison of four different types of ear: unoperated, ventilation tube alone, adenoidectomy alone, and adenoidectomy in combination with a tube.

Fluid was said to persist until the ear was reported otoscopically dry or there was persistence of $\mathrm{A}, \mathrm{C} 1$, or C2 tympanometric peaks on consecutive visits for a period in excess of 12 months. The time was taken to be half way through the interval incorporating the change -for example, for a child in whom fluid was reported at year 3 but not at years 4 and 5 the fluid survival time was estimated to be 3.5 years.

Data from children whose ears contained fluid at the final assessment or at the last assessment before they were lost to follow up were excluded. Data were also excluded when the child developed severe obstructive symptoms from enlargement of the adenoids or tonsils, often with sleep apnoea that required surgical treatment, and when surgery was required to the unoperated ear-for example, insertion of a ventilation tube for severe collapse of the tympanic membrane or for treatment of cholesteatoma. Eleven children were excluded because of severe problems in the operated ear, which was treated by insertion of a long stay Goode type tympanostomy tube instead of a Shepard tube.

Obviously excluding more severe cases results in bias because the remainder are less severe. Table II, however, shows that most excluded cases were from the no surgery group. The principle of intention to treat was not used in this analysis as the purpose was evaluation of the untreated condition and the effects of treatments rather than their feasibility.

During the follow up period there were only five ears in which fluid recurred and persisted for at least one year after they had been clear for at least one year. All had been operated on, four of them by combined adenoidectomy and insertion of a tube and one by insertion of a tube only.

\section{STATISTICAL ANALYSIS}

The mean number of tubes inserted and the mean follow up time for each group were compared by using Student's $t$ test. Survival analysis was carried out with the Kaplan-Meier product limit method, and the log rank test was used to test the significance of differences between the treatment groups. Potential prognostic factors were investigated with Cox's proportional hazards regression model. Regression coefficients were exponentiated to produce estimated relative hazards. We calculated $95 \%$ confidence intervals for these hazards and used $\chi^{2}$ to test the overall significance of the association of the categorical variables with survival. Prognostic factors for mean hearing thresholds were tested for significance with analysis of covariance. All the statistical computations were performed with the SAS software system. ${ }^{\circ}$

\section{Results}

The number of insertions of Shepard ventilation tubes was recorded for each child, and it became apparent that ears treated with tubes alone required significantly more tubes (mean 2.48 , SD 1.39 ) than 
those receiving tubes in combination with adenoidectomy $(1.52,0.85 ; p=0.0001)$. This was in spite of a longer mean time till exclusion or end of follow up for the adenoidectomy cases. Follow up irrespective of exclusion was equivalent in the two groups (nonadenoidectomy cases mean (SD) $7.0(2.5)$ years and adenoidectomy cases $7 \cdot 2(2 \cdot 6)$ years; $\mathrm{p}=0 \cdot 7)$.

\section{DURATION OF GLUE EAR}

The survival curves for both otoscopic (fig 1) and tympanometric assessments (fig 2) clearly show that fluid remains longest in the no surgery group. This is followed by the ventilation tube only group and the adenoidectomy only group, whose survival curves are not significantly different. The combined adenoidectomy and ventilation tube groups had the shortest duration of glue ear. Table III shows the $p$ values for the $\log$ rank tests of equality of survival between each pair of treatments. There is a clear benefit of all three treatments over no surgery in terms of duration of fluid. There is no difference overall between adenoidectomy only and ventilation tubes alone but a significant benefit of adenoidectomy and tube insertion in combination above any other treatment.

\section{PROGNOSTIC FACTORS}

By using forward stepwise Cox regression analysis, age at operation, tonsillectomy, and radiographic size of adenoids and airway were not significantly related to the duration of glue ear in either of the surgery or no surgery groups. Parental smoking, age at onset, and duration of hearing loss before operation, however, were significant and are therefore included in the

TABLE III-p Values for log rank tests of equality of survival between each pair of treatments for glue ear

\begin{tabular}{lccc}
\hline & & \multicolumn{2}{c}{ Adenoidectomy } \\
\cline { 3 - 4 } & Tube(s) only & Alone & With tube(s) \\
\hline No surgery: & & & \\
Otoscopy & 0.006 & 0.0001 & 0.0001 \\
$\quad$ Tympanometry & 0.002 & 0.0001 & 0.0001 \\
Tube(s) only: & - & 0.25 & 0.0001 \\
$\quad$ Otoscopy & - & 0.21 & 0.0002 \\
$\quad \begin{array}{l}\text { Tympanometry } \\
\text { Adenoidectomy only: }\end{array}$ & & - & 0.0001 \\
$\quad$ Otoscopy & & - & 0.001 \\
$\quad$ Tympanometry & & - & \\
\hline
\end{tabular}

TABLE IV-Variables used in Cox's regression analysis for adenoidectomy and no surgery groups

\begin{tabular}{|c|c|c|c|c|}
\hline Variable & Category & No surgery & Adenoidectomy & Total \\
\hline Sex & $\begin{cases}0 & (\mathrm{~F}) \\
1 & (\mathrm{M})\end{cases}$ & $\begin{array}{l}28 \\
38\end{array}$ & $\begin{array}{l}41 \\
81\end{array}$ & $\begin{array}{r}69 \\
119\end{array}$ \\
\hline Parental smoking ${ }^{\star}$ & $\begin{cases}0 & \text { Neither smoke }) \\
1 & (1 \text { Or both smoke) }\end{cases}$ & $\begin{array}{l}21 \\
45 \\
13\end{array}$ & $\begin{array}{l}49 \\
73 \\
26\end{array}$ & $\begin{array}{r}70 \\
118 \\
39\end{array}$ \\
\hline Age at onset of hearing loss (years) & $\left\{\begin{array}{l}1(\leqslant 2 \cdot 5) \\
2(>2 \cdot 5, \leqslant 4) \\
3(>4)\end{array}\right.$ & $\begin{array}{l}13 \\
35 \\
18\end{array}$ & $\begin{array}{l}26 \\
53 \\
43\end{array}$ & $\begin{array}{l}39 \\
88 \\
61\end{array}$ \\
\hline $\begin{array}{l}\text { Duration of preoperative hearing loss } \\
\text { (years) }\end{array}$ & $\begin{cases}1 & (\leqslant 1) \\
2 & (>1, \leqslant 2) \\
3 & (>2)\end{cases}$ & $\begin{array}{l}18 \\
23 \\
25\end{array}$ & $\begin{array}{l}30 \\
45 \\
47\end{array}$ & $\begin{array}{l}48 \\
68 \\
72\end{array}$ \\
\hline
\end{tabular}

${ }^{\star}$ Data missing for 25 children, therefore only 66 in no surgery group and 122 in adenoidectomy included in analysis.

TABLE V-Results from regression analysis for otoscopic assessments for the untreated groups of ears and no surgery ears. Figures are hazard rates * (95\% confidence intervals)

\begin{tabular}{|c|c|c|c|}
\hline Variable & Category & No surgery $(n=66)$ & Surgery $(n=310)$ \\
\hline Adenoidectomy only & $\left\{\begin{array}{l}\text { Yes } \\
\text { No }\end{array}\right.$ & - & $\begin{array}{l}1.14(0.80 \text { to } 1.62)(p=0.5) \\
1.00\end{array}$ \\
\hline Adenoidectomy and tube & $\left\{\begin{array}{l}\text { Yes } \\
\text { No }\end{array}\right.$ & - & $\begin{array}{l}2.18(1.53 \text { to } 3.10)(p=0.0001) \\
1.00\end{array}$ \\
\hline Sex & $\left\{\begin{array}{l}M \\
\mathrm{~F}\end{array}\right.$ & $\begin{array}{l}0.96(0.50 \text { to } 1.86)(p=0.9) \\
1.00\end{array}$ & $\begin{array}{l}0.89(0.68 \text { to } 1.15)(p=0.4) \\
1.00\end{array}$ \\
\hline Parental smoking & $\left\{\begin{array}{l}\text { Yes } \\
\text { No }\end{array}\right.$ & $\begin{array}{l}0.44(0.22 \text { to } 0.87)(p=0.02) \\
1.00 \\
0.66(0.26 \text { to } 1.72)(p=0.4)\end{array}$ & $\begin{array}{l}0.61(0.47 \text { to } 0.79)(p=0.0002) \\
1.00 \\
0.40(0.28 \text { to } 0.59)(p=0.0001)\end{array}$ \\
\hline Age at onset of hearing loss & $\left\{\begin{array}{l}1 \\
2 \\
3\end{array}\right.$ & $0.84(0.40$ to 1.78$)(p=0.7)$ & $\begin{array}{l}0.83(0.63 \text { to } 1.10)(p=0.2) \\
1.00\end{array}$ \\
\hline Duration of preoperative hearing loss & $\left\{\begin{array}{l}1 \\
2 \\
3\end{array}\right.$ & $\begin{array}{l}0.97(0.35 \text { to } 2.73)(\mathrm{p}=1.0) \\
1.25(0.59 \text { to } 2.66)(\mathrm{p}=0.6) \\
1.00\end{array}$ & $\begin{array}{l}1.77(1.27 \text { to } 2.47)(p=0.0008) \\
1.68(1.26 \text { to } 2.25)(p=0.0004) \\
1.00\end{array}$ \\
\hline
\end{tabular}

*Values $>1$ indicate increased chance of fluid clearing; values $\leqslant 1$ indicate a decreased chance.

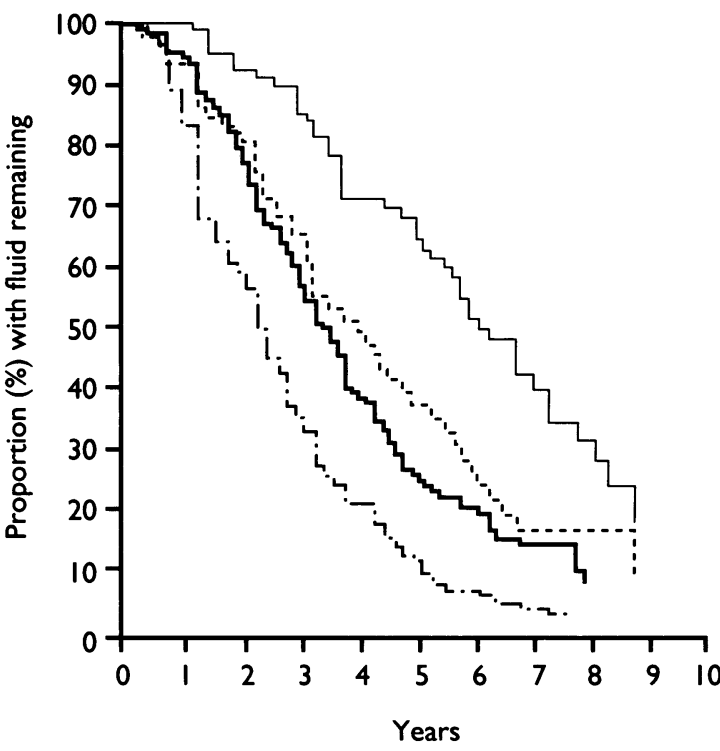

FIG 1-Survival functions for time to fluid clearance as confirmed by otoscopy ( $\_$no surgery $(n=77) ; \ldots . . . .$. ventilation tube only $(n=77)$; adenoidectomy only $(n=136) ; \ldots . . . .$. adenoidectomy and tube $(n=136))$

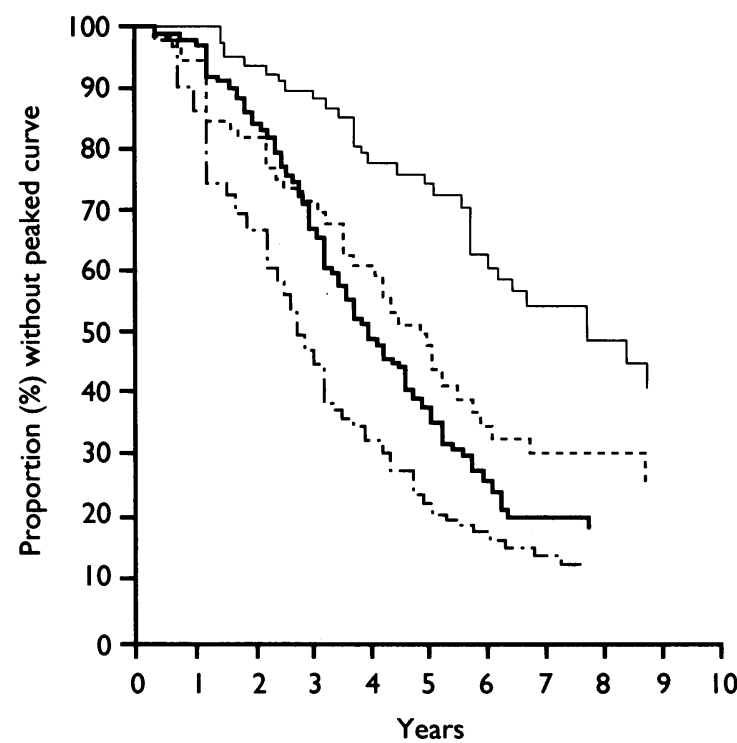

FIG 2-Survival functions for time to tympanometric peak (_ no surgery $(n=77)$; ........ ventilation tube only $(n=77)$; tomy only $(n=136) ; . . . . . .$. adenoidectomy and tube $(n=136))$

models. Sex is also included as a controlling factor, although it was not significant.

The variables were categorised (table IV), and hazard rates were estimated relative to a baseline category (table V). Regression analyses were carried out based on the results of both otoscopy and tympanometry but only those for otoscopic findings are reported to avoid repetition. The only factor affecting the no surgery group was parental smoking. Fluid in the ears of children whose parents did not smoke was more than twice as likely to clear than fluid in the ears of those whose parents did smoke.

For ears treated surgically there was no significant advantage of adenoidectomy alone over the baseline category of tube insertion alone. Fluid in the ears of children receiving adenoidectomy and a tube, however, was more than twice as likely to clear than fluid in those receiving either procedure alone.

Once again parental smoking was detrimental to the clearance of fluid, and the sex of the child was not significant. Those aged $2 \frac{1}{2}$ years or less at the onset of hearing loss fared considerably less well than their older counterparts. Table $\mathrm{V}$ also shows that the longer glue ear had been present before the operation the longer the overall duration of the condition. This 
suggests that early surgery would substantially reduce the overall time with fluid.

\section{HEARING THRESHOLDS}

The improvement in mean hearing threshold since the preoperative assessment was calculated for each child at each follow up. Table VI shows the mean results and the maximum possible number of valid observations for each group at each time point. These decline due to exclusions made during follow up.

Analysis of covariance for possible factors affecting mean hearing thresholds was carried out for each of the four different types of ear. Age at onset of hearing loss, sex, parental smoking, postnasal airway size measured by radiography, and duration of preoperative hearing loss were not significant. Each model included presence or absence of fluid, presence or absence of tympanometric peak, age at operation (mean (SD) 5.48 $(1 \cdot 12)$ years), and size of adenoids measured by radiography $(1.48(0.29) \mathrm{cm})$. Follow up at seven and 10 years was excluded from this analysis because of the small amount of data for the models.

For all groups the main determinant of improvement in mean hearing threshold was the otoscopic presence or absence of fluid. The resolution of fluid made a difference of between 4.2 (SE 4.4$) \mathrm{dB}$ and 21.2 $(4 \cdot 2) \mathrm{dB}$. The improvement was significant at the $5 \%$ level on at least four of the six follow ups considered for each type of ear.

The presence of a peak was also shown to be significantly beneficial on several occasions, particularly in the adenoidectomy only group (maximum effect 7.6 (SE 2.4) dB). Age at operation was found to be significant only for the adenoidectomy only group, with those who were older at operation facing a minor disadvantage (about $2 \mathrm{~dB}$ ) between three and five years postoperatively.

Size of adenoids affected the gains in mean hearing thresholds of only those children receiving adenoidectomy. An improvement of up to $13 \cdot 1$ (SE 2.6) $\mathrm{dB}$ was shown per $\mathrm{cm}$ size of adenoids removed.

\section{Discussion}

Our previous work ${ }^{23}$ and that of others ${ }^{7}$ has shown the spontaneous resolution of glue ear in the short term. Our previously reported resolution rate at two to three years ${ }^{8}$ was similar to that of Leiberman and Bartal, ${ }^{9}$ who found clearance in $31 \%$ of 158 children with middle ear effusions untreated for two and a half years. No data exist for outcome of the untreated chronic condition followed for more than five years. Our study shows the long term spontaneous resolution of severe glue ear in children. They had a history of hearing loss for an average of 18 months. Fluid was present in both ears at three examinations over three months and was confirmed by a validated otoscopist and by tympanometry. Nevertheless, without any treatment the condition improved as time passed.

As seen from table VI, the recall rates at five years were between $74 \%$ and $84 \%$, at seven years between $51 \%$ and $64 \%$, and at 10 years between $29 \%$ and $35 \%$. They were low in the later years partly because recruitment continued until 1986 and partly because of non-attendance.

Survival analysis showed similar improvements in otoscopic clearance and tympanometric change as a result of treatment with a ventilation tube alone or after adenoidectomy alone compared with no surgery. Further improvement resulted from the combination of both adenoidectomy and insertion of tubes. The median duration of glue ear assessed otoscopically reduced from $6 \cdot 1$ years without surgery to 3.5 years with tubes, 3.4 years after adenoidectomy, and 2.3 years with the combination of adenoidectomy and
TABLE VI-Mean (SD) hearing thresholds and subsequent improvements after intervention or no intervention

\begin{tabular}{|c|c|c|c|}
\hline Time & $\begin{array}{l}\text { No of } \\
\text { children }\end{array}$ & $\begin{array}{c}\text { Maximum } \\
\text { possible }\end{array}$ & $\begin{array}{c}\text { Mean (SD) } \\
\text { hearing } \\
\text { threshold }\end{array}$ \\
\hline \multicolumn{4}{|c|}{ No surgery* } \\
\hline $\begin{array}{l}\text { Before operation } \\
6 \text { Months } \\
1 \text { Year } \\
2 \text { Years } \\
3 \text { Years } \\
4 \text { Years } \\
5 \text { Years } \\
7 \text { Years } \\
10 \text { Years }\end{array}$ & $\begin{array}{l}73 \\
59 \\
66 \\
62 \\
57 \\
53 \\
49 \\
38 \\
19\end{array}$ & $\begin{array}{l}73 \\
71 \\
71 \\
65 \\
59 \\
56 \\
56 \\
55 \\
52\end{array}$ & $\begin{array}{c}31 \cdot 86(8 \cdot 89) \\
3 \cdot 60(10 \cdot 15) \\
4 \cdot 88(11 \cdot 11) \\
7 \cdot 57(12 \cdot 76) \\
9 \cdot 47(10 \cdot 26) \\
13 \cdot 65(9 \cdot 70) \\
14 \cdot 79(8 \cdot 82) \\
15 \cdot 81(9 \cdot 45) \\
16 \cdot 52(10 \cdot 33)\end{array}$ \\
\hline \multicolumn{4}{|c|}{ Tube onlyt } \\
\hline $\begin{array}{l}\text { Before operation } \\
6 \text { Months } \\
1 \text { Year } \\
2 \text { Years } \\
3 \text { Years } \\
4 \text { Years } \\
5 \text { Years } \\
7 \text { Years } \\
10 \text { Years }\end{array}$ & $\begin{array}{l}73 \\
59 \\
66 \\
60 \\
51 \\
48 \\
43 \\
32 \\
15\end{array}$ & $\begin{array}{l}73 \\
71 \\
71 \\
65 \\
56 \\
53 \\
51 \\
50 \\
48\end{array}$ & $\begin{array}{l}30 \cdot 90(8 \cdot 98) \\
15 \cdot 51(9 \cdot 16) \\
13 \cdot 06(9 \cdot 49) \\
12 \cdot 24(9 \cdot 10) \\
12 \cdot 77(10 \cdot 47) \\
14 \cdot 13(8 \cdot 27) \\
15 \cdot 30(7 \cdot 59) \\
18 \cdot 13(6 \cdot 64) \\
16 \cdot 04(7 \cdot 88)\end{array}$ \\
\hline \multicolumn{4}{|c|}{ Adenoidectomy only $\neq$} \\
\hline $\begin{array}{l}\text { Before operation } \\
6 \text { Months } \\
1 \text { Year } \\
2 \text { Years } \\
3 \text { Years } \\
4 \text { Years } \\
5 \text { Years } \\
7 \text { Years } \\
10 \text { Years }\end{array}$ & $\begin{array}{r}118 \\
92 \\
113 \\
88 \\
101 \\
93 \\
85 \\
60 \\
40\end{array}$ & $\begin{array}{l}118 \\
118 \\
118 \\
117 \\
117 \\
116 \\
115 \\
114 \\
113\end{array}$ & $\begin{array}{l}31.54(8.93) \\
12 \cdot 18(10 \cdot 41) \\
12 \cdot 48(9 \cdot 73) \\
14 \cdot 46(10 \cdot 74) \\
16 \cdot 68(9 \cdot 01) \\
16 \cdot 89(9.98) \\
17 \cdot 00(10 \cdot 50) \\
19 \cdot 12(9 \cdot 75) \\
18 \cdot 43(8.85)\end{array}$ \\
\hline \multicolumn{4}{|c|}{ Adenoidectomy and tube } \\
\hline $\begin{array}{l}\text { Before operation } \\
6 \text { Months } \\
1 \text { Year } \\
2 \text { Years } \\
3 \text { Years } \\
4 \text { Years } \\
5 \text { Years } \\
7 \text { Years } \\
10 \text { Years }\end{array}$ & $\begin{array}{r}117 \\
91 \\
112 \\
87 \\
100 \\
91 \\
84 \\
58 \\
39\end{array}$ & $\begin{array}{l}118 \\
117 \\
117 \\
116 \\
116 \\
114 \\
113 \\
113 \\
113\end{array}$ & $\begin{array}{l}31 \cdot 51(8 \cdot 58) \\
15 \cdot 40(9 \cdot 77) \\
14 \cdot 12(9 \cdot 00) \\
15 \cdot 47(9 \cdot 35) \\
16 \cdot 29(8 \cdot 66) \\
15 \cdot 73(9 \cdot 11) \\
17 \cdot 26(9 \cdot 80) \\
17 \cdot 77(9 \cdot 41) \\
18 \cdot 10(7 \cdot 68)\end{array}$ \\
\hline
\end{tabular}

* Seventeen excluded after removal of adenoids and/or tonsils; four excluded after insertion of tubes.

tSeventeen excluded after removal of adenoids and/or tonsils; eight excluded after insertion of Goode tubes.

‡One excluded after insertion of tube, two excluded after myringotomy; two excluded for other reason such as pharyngoplasty.

$§$ Three excluded after insertion of Goode tubes; two excluded for other reasons.

tubes. Objective assessment with tympanometry shows longer durations because of its greater sensitivity compared with otoscopy $(7 \cdot 8$ years, 4.9 years, $4 \cdot 0$ years, and $2 \cdot 8$ years, respectively). Otoscopic and tympanometric improvement are shown to be associated with improvements in mean hearing thresholds.

Mean hearing thresholds are related mainly to the presence or absence of fluid in the middle ear. The gain in hearing for each treatment group at six and 12 months was similar to that shown in other comparable studies. ${ }^{1011}$ Some relation between size of adenoids and thresholds of hearing has also been shown. Children who have had large adenoids removed develop slightly better hearing thresholds than those who have had smaller adenoids removed.

Assessment of the effect of possible prognostic factors showed that children with parents who smoke and, in the case of surgical intervention, children who are younger $\left(<2^{1 / 2}\right.$ years) at onset of hearing loss have a less satisfactory outcome otoscopically and tympanometrically. Because surgery reduces the postoperative duration of the fluid the earlier it is performed the shorter is the overall duration of the condition. Unlike in other studies ${ }^{10}$ we did not find any perceptible effect due to sex.

These results agree with our other previously reported short term data in which the effect of adenoidectomy was related to the age of the child ${ }^{12}$ and, to a lesser extent, to the degree of nasopharyngeal obstruction caused by the adenoids. ${ }^{13}$ More recently we have shown morphological differences in the 
nasopharynx and base of the skull in children with glue ear, and these are probably related to age and growth. ${ }^{14}$

This study was designed to evaluate the effect of adenoidectomy and adenotonsillectomy compared with no surgery and thus the data on effectiveness of treatment with ventilation tubes are somewhat a byproduct. During the follow up a mean of 2.48 (1.39) tubes were required to maintain adequate hearing ability in those treated with tubes alone compared with a mean of $1.52(0.85)$ in the children also receiving adenoidectomy. The two ears may not react identically with respect to insertion and reinsertion of tubes. In this study the overall need for reinsertion may have been higher, particularly in the no surgery group, than if bilateral tubes had been used instead of one tube.

\section{RECOMMENDATIONS}

Based on the data from this and other work we can suggest certain recommendations for the clinical management of children with severe established glue ear.

Owing to the spontaneous resolution seen before and after operation all children with glue ear should be examined with pneumatic otoscopy and tympanometry on at least two occasions over three months before the decision to operate is made.

The decision to combine adenoidectomy with insertion of tubes should consider the additional morbidity and mortality and also the probable need for an overnight stay in hospital for adenoidectomy compared with a day case admission for tube insertion alone.

The child's age is important in relation to adenoidectomy. With increasing age the operation is more effective in resolving glue ear than in younger children, ${ }^{13}$ in whom such surgery may also be contraindicated for more general reasons of increased operative risk.

Initially insertion of tubes alone would be advisable in younger children with established glue ear unless there is coexisting gross adenoidal enlargement and chronic nasopharyngeal obstruction. Parents should, however, be advised that repeat treatment may be required, particularly when insertion is carried out alone.

Adenoidectomy will considerably reduce the overall duration of glue ear. Furthermore, it can be recommended more confidently in older children. We have shown that the combination of adenoidectomy with insertion of tubes provides immediate restoration of subjective hearing ability because of the tube; longer term sustained resolution because of adenoidectomy; and also a possible reduction in the need for subsequent insertions of new tubes.

If bilateral cases of glue ear are treated with adenoidectomy and tube insertion there may be a case for bilateral myringotomy and aspiration of fluid but with insertion of only a unilateral tube. This would reduce by half the complications due to tubes.

Finally, parents of children with glue ear should be advised to stop smoking.

1 Black N. Geographical variations in the use of surgery for glue ear. $f$ Roy Soc Med 1985;78:641-8.

2 Maw AR. Chronic otitis media with effusion (glue ear) and adenotonsillectomy: prospective randomised controlled study. $B M \mathcal{F} 1983 ; 287: 1586-8$.

3 Maw AR, Herod F. Otoscopic impedance and audiometric findings in glue ear treated by adenoidectomy and tonsillectomy. Lancet 1986;i:1399-402.

4 Stephenson H, Haggard M. Rationale and design of surgical trials for otitis media with effusion. Clin Otolaryngol 1992;17:67-78.

5 Maw AR. Preliminary findings for inter-observer variability in children with middle ear effusions and adenoids. Clin Otolaryngol 1979;4:149.

6 SAS Institute. SAS user's guide. Statistics version. 5th ed. Cary, North Carolina: SAS Institute, 1985.

7 Buckley G, Hinton A. Otitis media with effusion in children shows a progressive resolution with time. Clin Otolanyngol 1991;16:354-7.

$8 \mathrm{Maw}$ AR, Parker A. Surgery to the tonsils and adenoids in relation to secretory otitis media in children. Acta Otolaryngol (Stockh) 1988;454(suppl):202-7.

9 Leiberman A, Bartal N. Untreated persistent middle ear effusion. 7 Laryngol Otol 1986;100:875-8.

10 Dempster JH, Browning GG, Gatehouse SG. A randomised study of the surgical management of children with persistent otitis media with effusion associated with a hearing impairment. $f$ Laryngol Otol (in press).

11 Black NA, Sanderson CF, Freeland AP, Vessey MP. A randomised controlled trial of surgery for glue ear. $B M \mathcal{F} 1990 ; 300: 1551-6$.

12 Parker AJ, Maw AR. Treatment of glue ear in relation to radiographic palatal airway size: a predictor for outcome following adenoidectomy. $f$ Laryngol Otol 1989;103:66-70.

13 Maw AR. Age and adenoid size in relation to adenoidectomy in otitis media with effusion. Am 7 Otolaryngol 1985;6:245-8.

14 Maw AR, Smith IM, Lance GN. Lateral cephalometric analysis of children with otitis media with effusion: a comparison with age and sex matched controls. ₹ Laryngol Otol 1991;105:71-7.

(Accepted 25 fanuary 1993)
Health Psychology

Research Unit, School of

Psychology, University of

Wales College of Cardiff, Cardiff CF1 3YG

Andrew P Smith, director

Marie Thomas, research

assistant

Pip Brockman, research

assistant

Department of

Microbiology, Leicester

University, Medical

Sciences Building,

Leicester LE1 7RH

Julie Kent, technician

Karl G Nicholson, senior

lecturer

Correspondence to:

Dr Smith.

$B M \mathcal{F} 1993 ; 306: 760-1$

\section{Effect of influenza $B$ virus infection on human performance}

\author{
Andrew P Smith, Marie Thomas, Pip Brockman, \\ Julie Kent, Karl G Nicholson
}

Anecdotal evidence suggests that influenza reduces people's safety and efficiency in their workplace. Studies of experimentally induced influenza B in volunteers at the Medical Research Council Common Cold Unit showed that infection increased reaction times to stimuli occurring at varying intervals but that hand-eye coordination was unimpaired. ${ }^{1}$ We report the results of two studies to determine whether natural influenza B similarly prolongs human reaction times and whether other performance indicators are affected.

\section{Subjects, methods, and results}

Altogether 178 volunteers aged 18-30 were studied. The studies were approved by the ethics committee, and all volunteers gave written informed consent. On recruitment to the first study 92 healthy subjects rated their mood and performed various tasks (a variable fore period simple reaction time task, five choice serial response task, repeated numbers detection task, free recall test, delayed recognition memory test, logical reasoning test, focused attention task, and categoric search task) that have been described previously. ${ }^{23}$ Subjects who developed a symptomatic infection of the upper respiratory tract were retested while ill and again one month later when asymptomatic. Subjects who remained healthy (controls) were retested two and three months after recruitment. On recruitment to the second study 86 subjects, some of whom had symptomatic infections, rated their mood and performed 10 minute versions of the simple reaction time task and serial response task. Subjects were retested one month later.

A nasopharyngeal swab and blood sample for virological testing were collected from all symptomatic subjects, and a blood sample was collected from convalescent subjects four to six weeks later. A nasopharyngeal swab or paired serum samples, or both, were collected from healthy subjects. All specimens were coded before virological testing. Analyses of covariance were carried out in the first study, and $t$ tests were used in the second study.

In the first study four of the 26 subjects with symptomatic infections had influenza $B$ and showed a $38 \%$ increase in the mean time taken for the variable fore period simple reaction time task, from 320 (SD 24) $\mathrm{ms}$ when recruited to 440 (SD 90) $\mathrm{ms}$ when symptomatic. One month later, when the subjects were asymptomatic, their reaction time had fallen 